\title{
PROMOCIONANDO SALUD EN ADOLESCENTES
}

Promoting Adolescent Health

Fecha de Recepción: 06 de julio 2019
Promovendo a saúde do adolescente

Aceptado para su publicación: 13 de agosto 2019

\section{Autores: \\ Gabriela G. Bessone María C. Affur Karina E. Trangoni}

Área Disciplinar Introducción a la Odontología. Módulo Morfofunción I. Facultad de Odontología. Universidad Nacional del Nordeste. Argentina.

Correspondencia:

Gabriela G. Bessone

\section{Correo electrónico:}

gbessone@odn.unne.edu.ar

gabibessone@msn.com

Conflicto de intereses:

los autores declaran no tener conflictos de interés.

Fuente de financiamiento:

Programa Universidad en el Medio. Secretaría General de Extensión Universitaria.

UNNE.

\section{Resumen}

Adolescencia es el período de la vida comprendido entre la aparición de la pubertad, que marca el final de la infancia y el inicio de la edad adulta, momento en que se ha completado el desarrollo del organismo. Es una etapa de crecimiento físico y emocional que plantea nuevos paradigmas vinculados al cuidado de la salud y que los adolescentes deben conocer, para incorporar hábitos saludables que los protejan de posibles patologías. Es por ello, que el propósito de este proyecto fue difundir las enfermedades bucodentales más frecuentes de los adolescentes, a fin de disminuir la pérdida de piezas dentarias. Para ello, se realizaron charlas de educación para la salud utilizando material multimedia, talleres para la aplicación de técnicas de revelado de placa bacteriana y su posterior observación y remoción, ejercitación de técnica de cepillado correcta y topicaciones con flúor. Por otra parte, se trabajó la importancia de una dieta saludable, incentivando el cultivo y valor nutritivo de los alimentos orgánicos, aprovechando el recurso con el que cuentan, específicamente los estudiantes de ERAGIA. Las jornadas han permitido brindar conocimiento a los destinatarios y adquirir hábitos de higiene dental, lo que posibilitará su accionar como agentes multiplicadores.

Palabras clave: adolescencia, promoción de la salud, hábitos.

\section{Abstract}

Adolescence is the life time between the onset of puberty, which marks the that determines the onset of puberty, that points out the end of childhood and the beginning of adulthood, when the development of the organism has been completed. It is a stage of physi- 
cal and emotional growth that raises new paradigms linked to health care and that adolescents must know very well, to incorporate healthy habits that protect them from possible pathologies. That is because, the purpose of this project was to spread the most frequent oral diseases of adolescents, in order to reduce the loss of dental pieces. To achieve this main aim, we did health education talks were held using multimedia material, workshops for the application of bacterial plaque development techniques and their subsequent observation and removal, exercise of proper brushing technique and fluoride topications. On the other hand, we worked on the importance of a healthy diet, encouraging the cultivation and nutritional value of organic foods, taking advantage of the resources they have, specifically the ERAGIA students. The sessions have allowed to provide knowledge to the recipients and acquire habits of dental hygiene, which will enable their actions as multiplying agents.

Key words: adolescence, health promotion, habits.

\section{Resumo}

A adolescência é o perío do de vida entre o início da puberdade, marca o final da infância, e o início da idade adulta, quando o desenvolvimento do corpo foi concluído. É um estágio de crescimento físico e emocional que levanta novos paradigmas ligados à saúde e que os adolescentes devem conhecer, incorporando hábitos saudáveis que os protejam de possíveis patologias. Por isso, o objetivo deste projeto foi divulgar as doenças bucais mais frequentes dos adolescentes, a fim de reduzir a perda de peças dentárias. Para este fim, foram realizadas palestras sobre educação em saúde, utilizando material multimídia, oficinas para conhecer técnicas de revelado da placa bacteriana e sua posterior observação e remoção, exercício de técnica de escovação adequada e tópicos de flúor. Por outro lado, também se trabalhou a importância de uma alimentação saudável, incentivando o cultivo e valor nutricional dos alimentos orgânicos, aproveitando os recursos que possuem, especificamente os alunos da ERAGIA. As sessões permitiram proporcionar conhecimento aos destinatários e adquirir hábitos de higiene bucal, o que possibilitará suas ações como agentes multiplicadores.
Palavras-chave: adolescência, promoção da saúde, hábitos.

\section{Introducción}

La educación para la salud ha sido definida por la Organización Mundial de la Salud como la encargada de promover, organizar y orientar los procesos educativos tendientes a influir en los conocimientos, actitudes y prácticas relacionadas con la salud del individuo y la comunidad ${ }^{1}$.

La adolescencia es la etapa de la vida que comienza al terminar la infancia, culminando cuando el organismo alcanza su total desarrollo y empieza la edad adulta ${ }^{2}$. Los adolescentes representan un grupo etario vulnerable a los problemas de salud y la salud bucal, no está exenta de esta problemática, debido en gran parte al desconocimiento de los factores de riesgo y a la falta de información ${ }^{3-4}$.

En la adolescencia, con la erupción de los segundos molares se completa la dentición permanente pero se inicia un periodo de alto riesgo para la aparición de caries y enfermedad periodontal, por lo que resulta indispensable y efectiva, la intervención que se pueda realizar en esta etapa de la vida, ya que todo el conocimiento adquirido a través de educación y promoción de la salud, permitirá a los adolescentes, modificar actitudes que resulten perjudiciales para su salud bucal y general. Por ello, el propósito de este trabajo fue lograr la apropiación de hábitos saludables en los adolescentes, para que puedan transmitirlos a sus pares y al núcleo familiar, para mejorar la salud bucodental.

\section{Objetivos}

El objetivo general de este trabajo fue difundir cuáles son las enfermedades que afectan a los dientes y tejidos peridentarios en la adolescencia e incorporar hábitos saludables para prevenirlas. Los objetivos específicos fueron: 1) transmitir las causas que producen enfermedad en la cavidad bucal y las formas de prevenirlas; 2) motivar la práctica diaria de hábitos de higiene dental, mediante la visualización de placa bacteriana; 3) estimular el consumo de alimentos no cariogénicos; 4) disminuir las patologías bucodentales y evitar las pérdidas de piezas dentarias. 


\section{Metodología}

La Cátedra Introducción a la Odontología de la FOUNNE a través de la Secretaría de Extensión y dentro del marco del Programa UNNE en el Medio, viene desarrollando el proyecto "Promocionando Salud en Adolescentes", hace 4 años consecutivos. En el año 2015, se dio inicio a este trabajo de extensión, con la meta de capacitar a los estudiantes que cursen el primer año de la Escuela de Agricultura, Ganadería e Industrias afines - ERAGIA, de tal manera de instruir durante 5 años consecutivos a las cohortes que conforman toda la Institución.

El trabajo se ha realizado con 73 alumnos correspondientes al primer año de la Escuela, de entre 12 y 13 años de edad, de ambos sexos, provenientes de las provincias de Corrientes y Chaco, correspondientes al ciclo lectivo 2018.

Inicialmente se realizó una evaluación "ex-ante" para determinar el estado actual y realizar diagnóstico de la situación, a fin de poder direccionar las actividades a realizar.

Posteriormente las actividades fueron de carácter formativo y modalidad aula taller, organizadas en cuatro jornadas de trabajo, previamente pactadas con la Institución, de manera de trabajar con aproximadamente 35 alumnos por visita. Reunidos en el salón asignado por las autoridades, los docentes expusieron los temas a desarrollar acompañados de material multimedial. Luego, la actividad se realizó en pequeños grupos, donde los estudiantes participantes del equipo de trabajo, realizaron la demostración práctica de la técnica de cepillado de manera correcta y personalizada, mediante la utilización de macromodelos, con la ejercitación de los coparticipantes.

Una vez calibrada la técnica entre los presentes, se repartieron a los destinatarios pastillas revelantes para hacer visible la placa bacteriana, con el fin de observarla y registrarla mediante la elaboración de historias clínicas. Seguidamente se entregó un cepillo dental y un vasito descartable con agua corriente para la eliminación de la placa teñida y la realización de la higiene dental.

La documentación con la información recabada permitió hacer un análisis cuantificable del estado de salud bucal del grupo co-participante, de tal manera que en posteriores visitas se pudo evaluar el logro alcanzado.

\section{Resultados}

Se capacitó al $100 \%$ de los destinatarios en técnicas de higiene bucal y se logró visualizar y conocer la placa bacteriana, agente responsable de la iniciación de caries dental mediante el uso de pastillas revelantes.

Sobre un total de 73 estudiantes, se trabajó con 41 masculinos y 32 femeninos, de entre 12 y 13 años de edad, de los cuales el $87.7 \%$ no aplicaban una técnica de cepillado para el cuidado de sus dientes (Figura 1 y 2).

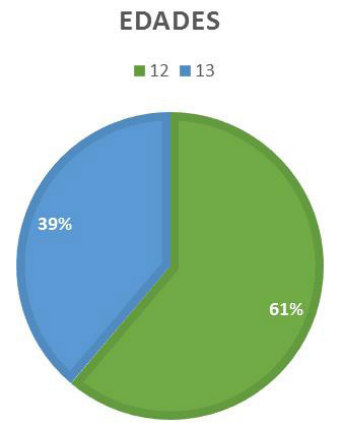

Figura 1. Edades de los participantes

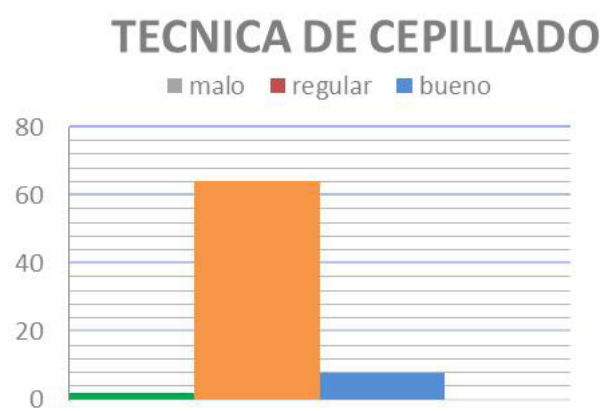

Figura 2. Técnica de cepillado que aplican diariamente. 


\section{EXTENSIÓN}

La mayor frecuencia de cepillado, fue de una vez al día (Figura 3).

Se estima que el $50 \%$ de los destinatarios, podrán actuar como agentes multiplicadores transmitiendo a su núcleo familiar y social, la información recibida.

El trabajo realizado, permitió que los miembros de la comunidad destinataria identifiquen los factores que desencadenan las enfermedades que afectan a la cavidad bucal y las formas de prevenirlas, impactando directa e indirectamente (Figura 4 y 5).

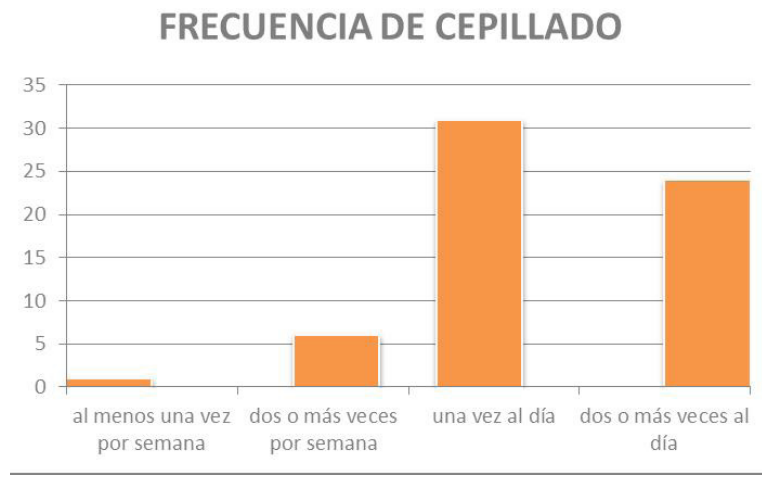

Figura 3. Frecuencia de cepillado diario

\section{Conclusiones}

La realización de éste Proyecto permitió que la población de adolescentes acceda a información actualizada sobre las afecciones de la cavidad bucal y las formas de prevenirlas. A través de la actividad taller realizada con los alumnos de la Escuela, se logró la exposición de inquietudes, erradicando dudas sobre cuestiones referidas a los temas trabajados, asumiendo el compromiso del cuidado de la salud bucodental, a través de la higiene bucal diaria y adecuada. La visualización de la placa bacteriana ha generado alto impacto en los destinatarios, permitiendo la toma de conciencia acerca de la importancia del cuidado de la salud bucodental.

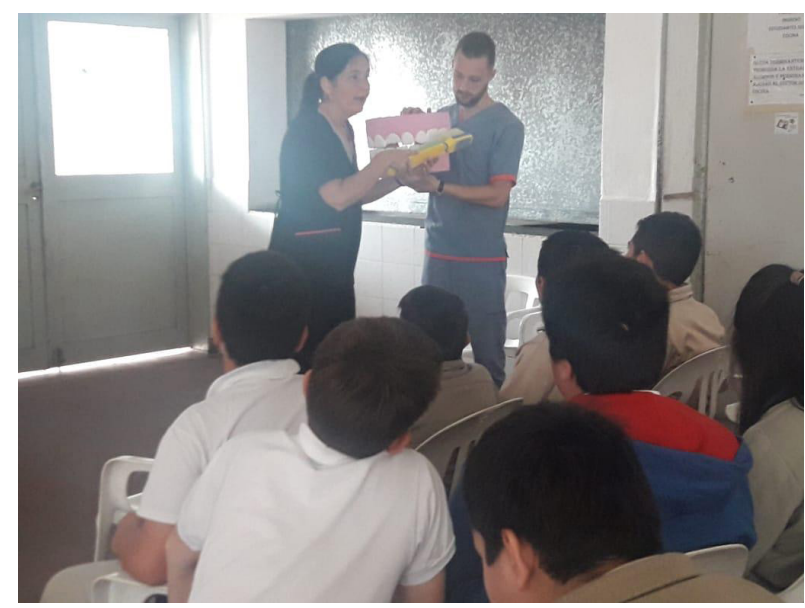

Figura 4. Charla a los destinatarios.

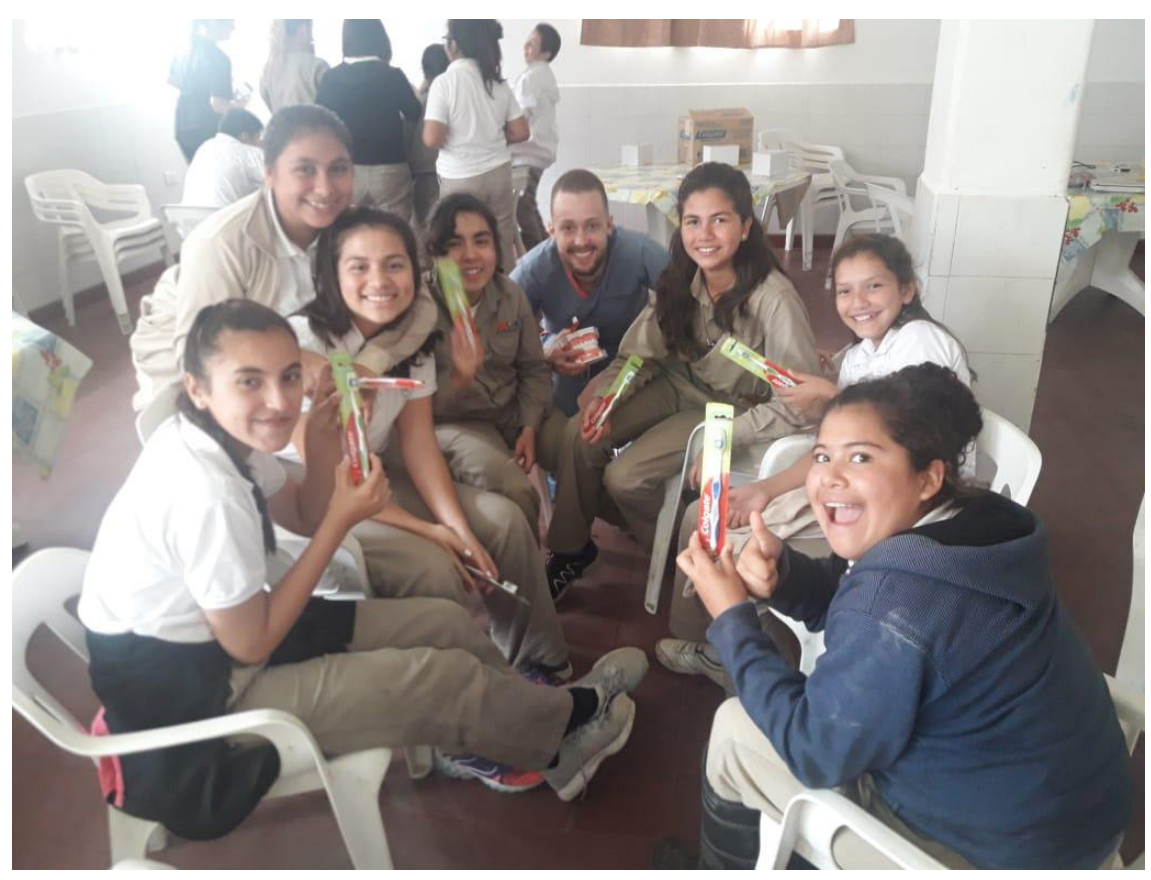

Figura 5. Trabajo grupal. 


\section{Referencias Bibliográficas}

1. Choque Larrauri R. Comunicación y educación para la promoción de la salud. [Internet]. Lima-Perú 2005 Dic [citado 2019 Jun 20]. Disponible en: <http://www.razonypalabra.org.mx/libros/libros/comyedusalud.pdf>

2. Chiu Navarro V. Afecciones buco dentales más frecuentes. En: Álvarez R. Temas de Medicina General Integral. La Habana. Ciencias Médicas; 2001. p. 631-4.

3. Martínez González F, Barrios Sierra CC, Salinas Morales LE. Conocimientos, actitudes y prácticas en salud bucal de padres y cuidadores en hogares infantiles, Colombia. Salud pública Méx [Internet]. 2011 [citado 2014 Ene 15]. Disponible en: http://www.redalyc.org/ pdf/211116129006.pdf

4. Rodríguez Llanes R, Traviesas Herrera EM, Lavandera Carballido $E$, Duque Hernández $M$. Factores de riesgo asociado con la caries dental en niños de círculos infantiles. Rev Cubana Estomatol [Internet]. 2009 [citado 2014 Feb 10]; 46(2). Disponible en: http://bvs.sld.cu/revistas/ est/vol46_2_09/est06209.htm

5. Lago Barney G. Las tecnologías de información y comunicación en el sistema de salud. Universitas Médica. 2008;49(2):151-154. Disponible en: https://www.redalyc.org/pdf/2310/231016364001.pdf

6. Katz S, McDonald JL, Stookey GK, Katz S Jr. Odontología preventiva en acción. Panamericana; Agencia para el Desarrollo Internacional. Buenos Aires, 1975.
7. OMS: Organización Mundial de la Salud. Promoción de la Salud. Glosario [Internet] Ginebra: WHO; 1998. WHO/ HPR/HEP/98.1.URL. Disponible en: http://www.bvs.org. ar/pdf/glosario_sp.pdf

8. OPS/OMS: Organización Panamericana de la Salud/ Organización Mundial de la Salud. Declaración de Yakarta sobre la Promoción de la Salud en el siglo XXI. 1997. Washington DC: Disponible en: https://www.who.int/ hpr/NPH/docs/jakarta_declaration_sp.pdf

9. Zurro AM, Cano Pérez JF, Gené Badia A. Atención Primaria: Principios, Organización y Métodos en medicina de familia. $7^{\text {a }}$ ed. España: Elsevier; 2014.

10. Cuenca Sala E, Baca García P. Odontología preventiva y comunitaria: principios, métodos y aplicaciones. $4^{\text {a }}$ ed. Barcelona: Elsevier Masson; 2005.

11. Kornblit AL, Mendes Diz AM, Di Leo PF, Camarotti AC. Entre la teoría y la práctica: algunas reflexiones en torno al sujeto en el campo de la promoción de la salud. Rev Argent Sociol. 2007;5(8):9-25. Disponible en: https://www. redalyc.org/pdf/269/26950802.pdf

12. Luetich A, Morini E, Cura A. Proyecto innovativo de educación para la salud bucal. Rev Ateneo Argent Odontol. 2002;39(1):5-9. 